\title{
Journal of Neuro and Oncology Research
}

Open Access

Research Article

\section{Effect of Bioceramic Derived Irradiation in Patients Suffering From Ataxia}

\author{
Elmar Weiler ${ }^{*}$, Dieter Schneider ${ }^{2}$ \\ ${ }^{1}$ NeuroNet/Nutris GmbH, Neurofeedback Therapie Zentrum, Parkstrasse 23, D-6606 Sankt Wendel, \\ Germany \\ ${ }^{2}$ Klinik und Poliklinik für Hals, Nasen und Ohrenkrankheiten, Plastische und Asthetische Operationen \\ Universität Würzburg Haus B2 Josef-Schneider-Str. 11 D-97080 Würzburg, Germany \\ *Corresponding Author: Elmar Weiler, NeuroNet/Nutris GmbH, Neurofeedback Therapie Zentrum, \\ Parkstrasse 23, D-6606 Sankt Wendel, Germany; Email: neuronet2009@web.de
}

Received Date: 12-09-2021; Accepted Date: 21-10-2021; Published Date: 28-10-2021

Copyright $^{\circledR} 2021$ by Weiler E, et al. All rights reserved. This is an open access article distributed under the terms of the Creative Commons Attribution License, which permits unrestricted use, distribution and reproduction in any medium, provided the original author and source are credited.

\begin{abstract}
Objectives: The objective of this study was to determine the efficacy of irradiation using an apparel with Far-Infrared Radiation (FIR) properties for the management of dizziness and unsteadiness.

Participants: The study comprised 20 patients with dizziness and unsteadiness.

Intervention: Cranio-Corpo-Graphy (CCG) was performed before and after wearing a bioceramic garment.

Results: Significant reduction of longitudinal and lateral movements was noted.

Conclusion: Subjects exhibiting dizziness and unsteadiness benefited significantly when wearing a garment with FIR properties. It is tempting to speculate that the bioceramic membrane exerts its effect via the parasympathetic branch. However, an impact on multiple cerebello-cerebral loops, via modulation of the excitability of residual cerebellar circuits could be discussed as a mechanism of action. The exact mechanism has yet to be determined.
\end{abstract}




\section{Keywords}

Bioceramic Membrane; Ataxia; Cranio-Corpo-Graphy

\section{Introduction}

C Far Infrared Radiation (FIR) is a subdivision of the electromagnetic radiation spectrum that has been investigated for biological effects [1]. The FIR band comprises the longest wavelengths $(\lambda=3-100 \mu \mathrm{m})$ of the infrared radiation band. In the past various studies provided evidence that far-infrared irradiation produces both non-thermal and thermal effects $[2,3]$.

Most recently bioceramic materials, materials that emit Far-Infrared (FIR) rays, have attracted increasing attention for therapeutic purposes [4]. Nanoparticles of such ceramic materials can be incorporated into fibers then woven into fabrics and manufactured into wearable apparel. The principle source of energy needed to power the FIR emission from the garments originates from the human body. Energy from the human body is transferred to these ceramic particles which are acting as "absorbers", maintain their temperature at sufficiently high levels and then emit FIR back to the body [1]. The body can experience energy of FIR as a radiant heat which can penetrate up to $4 \mathrm{~cm}$ beneath the skin. Elevation of skin temperature observed suggests that this might result in the acceleration of percutaneous blood circulation [5]. Such apparel has been linked to positive physiological effects. These wavelengths of far-infrared light may influence intracellular processes, affecting heat transfer in subcutaneous tissues and other physiologic processes [6,7]. Different studies implied that FIR irradiation can be an effectively employed for the treatment of patients suffering from phantom pain, fibromyalgia, postoperative pain, and chronic pain [8-16].

Decline of balance function is considered one of the factors likely to be responsible for falls in a large percentage of older adults [17-19]. As we age, balance function starts to decline and control of stance can become difficult for many older adults. In this context it is interesting to note that bioceramic fabrics improves postural control in young non-athlete participants and expert gymnasts [20]. Thus, it would be important to investigate whether bioceramic garments could improve balance stability in patients suffering from ataxia.

In ataxia, the fluid interplay of movement sequences is disturbed. This can affect gross motor processes such as walking or standing as well as fine-tuning the smallest muscle groups, for example when speaking or seeing. A distinction is therefore made between different forms of ataxia depending on the affected body region.

Ataxia is a generic term for various disorders of movement coordination, the process or the fine control of individual movements and the interplay of complex movement sequences. Ataxia can occur when the muscle strength is fully retained, but also in combination with symptoms of paralysis. When ataxia is not hereditary, it is mainly caused by damage to the cerebellum, brain stem, spinal cord, or peripheral nerves. The most obvious form of ataxia is gait ataxia or gait uncertainty. Affected people walk unsteadily, deviate from the straight gait

Weiler E | Volume 1; Issue 1 (2021) | JNOR-1(1)-002 | Research Article

Citation: Weiler E, et al. Effect of Bioceramic Derived Irradiation in Patients Suffering From Ataxia. J

Neuro Onco Res. 2021;1(1):1-8.

DOI: http://dx.doi.org/10.46889/JNOR.2021.1102 
or take safety steps to the side. Mainly involved are the cerebellum as the "center of equilibrium" and its connections to the cerebrum, the midbrain, the brain stem, the spinal cord, the organ of equilibrium, i.e. the labyrinth in the inner ear (vestibular apparatus) and the peripheral nerves. The cerebellum is particularly capable of coordinating the activity of various muscles in complex, often unconscious movements [21-23].

\section{Method}

To test the effect of bioceramic irradiation patients complaining of dizziness and unsteadiness were submitted to a so-called ultrasound Cranio-Corpo-Graphy (CCG) (Zebris Medical GmbH, Isny, Germany). Fundamental of the measurement is the provocative test of standing trial by Romberg. The Romberg test is used to diagnose disorders of balance and coordination of movements (ataxia). It has been clearly demonstrated that the Romberg test is an appropriate approach to measure the degree of disequilibrium caused by the central vertigo, peripheral vertigo and head trauma. Subject is asked to stand erect with feet together and eyes closed. The spatial positions are measured by ultrasonic transmitters; two of which determine the position of the head and the other two determine the position of the shoulder. The resulting pattern of movement of the head and body are recorded and allow during and after the measurement, a direct evaluation of the results. There is an automatic analysis of the longitudinal and lateral movements. The results are automatically calculated and archived. The measuring system consists of a sensor with stand, adapter, marker set (special marker helmet and shoulder markers) and the analysis software. Romberg's test is positive if there is a tendency to sway or fall when the eyes are closed, or if a tendency to sway or fall when the eyes are open increases [24-26]. Subsequently the recorded data are submitted to a statistical analysis. The basis of this test is the intact interaction of proprioception, vestibular input, and vision. In general, with at least two intact systems a person should exhibit a fair degree of balance. The key to the test is that vision is taken away, meaning the subject is asked to close the eyes. Thus, with only two of the three systems remaining, the patient will be become more imbalanced if a vestibular or a sensory disorder is present (Table 1).

Ataxia patients were recruited from ENT ward, university of Würzburg. Only patients with an anterior - lateral sway greater $11,5 \mathrm{~cm}$ and a lateral sway greater $10,5 \mathrm{~cm}$ and older than 18 years were allowed to participate in the study. Exclusion criteria were defined as follows: (a) sedative hypnotics, antidepressants, or anxiolytics less than 4 weeks; (b) patients with psychotic disorders, substance-related disorders, (c) abnormal laboratory tests of liver function and renal function; (d) pregnancy; (e) any physical or mental condition that, at the discretion of the examiner, does not allow safe or meaningful participation in the study (f) life expectancy $<3$ months, (g) unwillingness to sign the informed consent form.

Following the CCG baseline measurements the patients were requested to wear an apparel with FIR properties (AE2M GROUP CONTINO, Uxegney, France) for a minimum of 60 minutes before performing a second CCG measurement. 


\begin{tabular}{|c|c|c|}
\hline Gender & Number & Age \\
\hline Male & 9 & $67 \pm 9$ years \\
\hline Female & 11 & $63 \pm 9$ years \\
\hline
\end{tabular}

Table 1: Demographics of patients tested.

\section{Results}

The ultrasound CCG was performed in a total of 20 subjects all suffering from ataxia. In all cases the exposure to bioceramic irradiation lead to an improvement of the longitudinal and lateral sways. Below the case of a 72 year old male suffering from ataxia (cause unknown, duration 1 year) is illustrated. Patient was submitted to a CCG examination. The test was performed under the condition eyes closed without and with exposure to bioceramic irradiation (Fig. 1 and 2).

\section{Representative Case}

Without bioceramic membrane

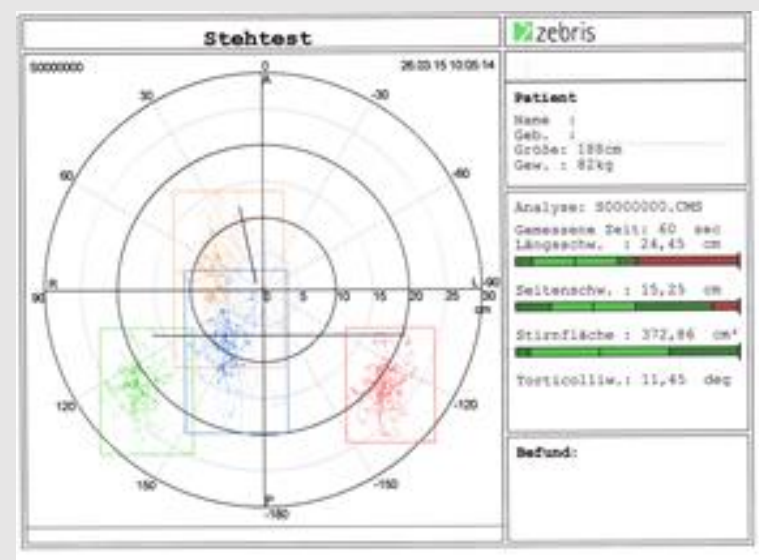

Figure 1: Illustration of longitudinal and lateral movements when subject is not exposed to bioceramic irradiation. 


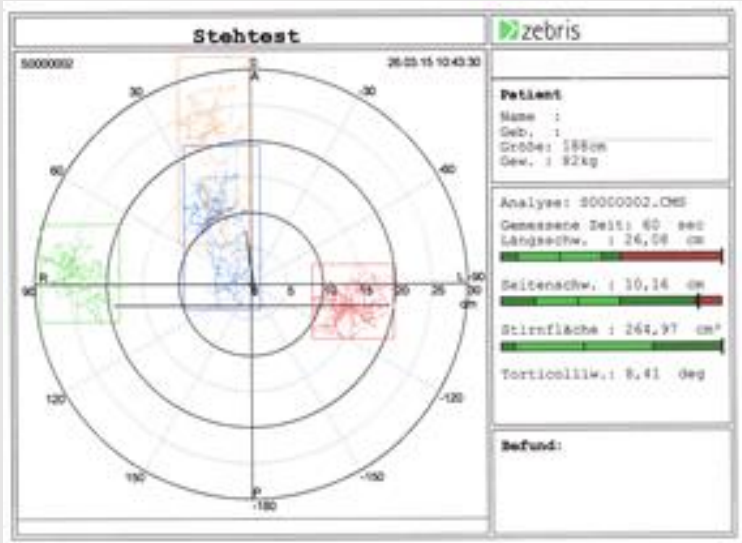

Figure 2: Illustration of longitudinal and lateral movements when subject is exposed to bioceramic irradiation.

The results of 20 patients subjected to CCG were submitted to a statistical analysis. The data analysis clearly indicated that bioceramic irradiation lead to a significant reduction of both the lateral and the longitudinal sways, however the strongest effect was noted for the lateral sway (Table 2).

\begin{tabular}{|c|c|c|c|}
\hline & $\begin{array}{c}\text { Without BCM Irradiation } \\
(\mathrm{n}=20)\end{array}$ & $\begin{array}{c}\text { With BCM Irradiation } \\
(\mathrm{n}=20)\end{array}$ & Significance \\
\hline Longitudinal sway & $16,62 \pm 3,15 \mathrm{~cm}$ & $13,27 \pm 3,83 \mathrm{~cm}$ & $\mathrm{p}<0,0001$ \\
\hline Lateral sway & $15,06 \pm 2,29 \mathrm{~cm}$ & $12,48 \pm 2,01 \mathrm{~cm}$ & $\mathrm{p}<0,0001$ \\
\hline
\end{tabular}

Table 2: Alterations induced on longitudinal and lateral sways (in patients suffering from ataxia) when exposed to bioceramic derived irradiation.

\section{Discussion}

Ataxias are disorders of the coordination of movements, which can be triggered by a variety of diseases such as spinocerebellar degeneration Multiple Sclerosis (MS) and stroke [39-42], thus, leading to a loss of function of certain parts of the nervous system [27-42]. Usually the cerebellum is affected, but damage to the spinal cord or peripheral nerves can also lead to ataxias. Diseases with loss of function of certain parts of the nervous system can cause ataxias. However, the most common cause is the damage to the cerebellum, which is responsible for coordinating information from the spinal cord, the organ of equilibrium and the other senses. The cerebellum translates this information into motor movements.

Damage to the cerebellum, resulting from an injury or illness (acquired ataxia) or because the cerebellum or spinal cord degenerates because of an inherited faulty gene (hereditary ataxia), 
will hamper its control functions concerning walking, sitting balance, limb co-ordination, eye movements and speech.

The main goal of therapies provided to patients with cerebellar ataxia is the recovery of motor function and activity of daily living. Therapies offered include medication, surgery and physical therapy [19,43-45].

Cause of ataxia and the extent of neuronal damage have a great impact on whether medication and surgery can be employed successfully $[46,47]$.

Most recently Transcranial Magnetic Stimulation (TMS) and transcranial Direct Current stimulation (tDCS)) were employed for treating patients with ataxia leading to an improvement of gait ataxia, limb ataxia, tremor, blood flow in the cerebellar hemisphere [48-52]. However, the extent of the above improvements remains moderate.

To our knowledge we are the first to describe a significant beneficial effect in patients suffering from ataxia when exposed to bioceramic derived irradiation. Both, the longitudinal as well as the lateral sways exhibited a significant change, thus leading to a much more stable gait and stands. It is assumed that the bioceramic derived irradiation provokes mainly an effect via the autonomic nervous system, most likely affecting the parasympathetic branch. However, bioceramic irradiation might also exhibit an impact on multiple cerebello-cerebral loops, via modulation of the excitability of residual cerebellar circuits, thus improving ataxia associated symptoms.

The results imply that garments with FIR properties can be an effective therapeutic approach in patients suffering from ataxia. However, further studies are needed in order to validate our findings.

\section{Conclusion}

Subjects exhibiting dizziness and unsteadiness benefited significantly when wearing a garment with FIR properties. It is tempting to speculate that the bioceramic membrane exerts its effect via the parasympathetic branch. However, an impact on multiple cerebello-cerebral loops, via modulation of the excitability of residual cerebellar circuits could be discussed as a mechanism of action. The exact mechanism has yet to be determined.

\section{References}

1. Vatansever F, Hamblin MR. Far infrared radiation (FIR): its biological effects and medical applications. Photonics Lasers Med. 2012;4:255-66.

2. Yu SY, Chiu JH, Yang SD. Biological effect of farinfrared therapy on increasing skin microcirculation in rats. Photodermatol Photoimmunol Photomed. 2006;22:78-86.

3. Inoue' SKM. Biological activities caused by far-infrared radiation. Int J Biometeorol. 1989;33:145-50.

4. Leung TK, Kuo CH, Lee CM, Kan NW, Hou CW. Physiological effects of bioceramic material: Harvard step, resting metabolic rate and treadmill running assessments. Chin J Physiol. 2013;56(6):334-40. 
5. Yoo HH, Kim YH, Cho HT, Shim HJ, Lee KB. Improvement of warmth retaining property of water vapor permeable/waterproof coated nylon fabric. J Korean Fiber Soc. 1993;30(3):250-8.

6. Leung TK, Lin YS, Chen YC, Shang HF, Lee YH, Su CH, et al. Immunomodulatory effects of far infrared ray irradiation via increasing calmodulin and nitric oxide production in RAW 264.7 macrophages. Biomed Eng Appl Basis Comm. 2009;21:317-23.

7. Leung TK, Lin YS, Lee CM, Chen YC, Shang HF, Hsiao SY, et al. Direct and indirect effects of ceramic far infrared radiation on hydrogen peroxide scavenging capacity and on murine macrophages under oxidative stress. J Med Biol Eng. 2011;31:345-51.

8. Huang CY, Yang RS, Kuo TS, Hsu KH. Phantom limb pain treated by far infrared ray. Conf Proc IEEE Eng Med Biol Soc. 2009;1589-91.

9. Matsushita K, Masuda A, Tei C. Efficacy of Waon therapy for fibromyalgia. Intern Med. 2008;47:1473-6.

10. Masuda A, Koga Y, Hattanmaru M, Minagoe S, Tei C. The effects of repeated thermal therapy for patients with chronic pain. Psychother Psychosom. 2005;74:288-94.

11. Wong CH, Lin LC, Lee HH, Liu CF. The analgesic effect of thermal therapy after total knee arthroplasty. J Altern Complement Med. 2012;18:175-9.

12. Beever R. The effects of repeated thermal therapy on quality of life in patients with type II diabetes mellitus. J Altern Complement Med. 2010;16:677-81.

13. Ko GD, Berbrayer D. Effect of ceramic-impregnated" thermoflow" gloves on patients with Raynaud's syndrome: randomized, placebo-controlled study. Alternative Med Rev. 20021;7(4):328-35.

14. CConrado LA, Munin E. Reduction in body measurements after use of a garment made with synthetic fibers embedded with ceramic nanoparticles. J Cosmetic Dermatol. 2011;10(1):30-5.

15. Lee CH, Roh JW, Lim CY, Hong JH, Lee JK, Min EG. A multicenter, randomized, double-blind, placebocontrolled trial evaluating the efficacy and safety of a far infrared-emitting sericite belt in patients with primary dysmenorrhea. Complementary Therapies Med. 2011;19(4):187-93.

16. York RM, Gordon IL. Effect of optically modified polyethylene terephthalate fiber socks on chronic foot pain. BMC Complementary and Alternative Med. 2009;9(10).

17. Shumway-Cook A, Brauer S, Woollacott M. Predicting the probability for falls in community-dwelling older adults using the Timed Up and Go Test. Phys Ther. 2000;80(9):896-03.

18. Shumway-Cook A, Woollacott M. Attentional demands and postural control: the effect of sensory context. J Gerontol A Biol Sci Med Sci. 2000;55(1):M10-6.

19. Tinetti ME, Williams CS. The effect of falls and fall injuries on functioning in community-dwelling older persons. J Gerontol A Biol Sci Med Sci. 1998;53(2):M112-9.

20. Cian C, Gianocca V, Barraud PA, Guerraz M, Bresciani JP. Bioceramic fabrics improve quiet standing posture and handstand stability in expert gymnasts. Gait and Posture. 2015;42(4):419-23.

21. Bastian AJ. Learning to predict the future: the cerebellum adapts feedforward movement control. Curr Opin Neurobiol. 2006;16(6):645-9.

22. Bastian AJ, Martin TA, Keating JG, Thach WT. Cerebellar ataxia: abnormal control of interaction torques across multiple joints. J Neurophysiol. 1996;76(1):492-09.

23. Vilis T, Hore J. Central neural mechanisms contributing to cerebellar tremor produced by limb perturbations. J Neurophysiol. 1980;43(2):279-91.

24. Lanska DJ, Goetz CG. Romberg's sign: development, adoption, and adaptation in the 19th century. Neurol. 2000;55(8):1201-6.

25. Panaretaki E, Kostadakos S, Hatzitaki V, Grouios G. Standing with one foot in front of the other (sharpened romberg position): footedness effect. Centro Esportivo Virtual.

26. Blumenfeld H. Romberg Test. neuroexam.com. http://www.neuroexam.com/content

27. Miyai I. Challenge of neurorehabilitation for cerebellar degenerative diseases. Cerebellum. 2012;11(2):4367.

28. Fonteyn EM, Heeren A, Engels JJ, Boer JJ, van de Warrenburg BP, Weerdesteyn V. Gait adaptability training improves obstacle avoidance and dynamic stability in patients cerebellar degeneration. Gait Posture. 2014;40(1):247-51.

29. Trujillo-Martín MM, Serrano-Aguilar P, Monton-Alvarez F, Carrillo-Fumero R. Effectiveness and safety of treatments for degenerative ataxias: a systematic review. Mov Disord. 2009;24(8):1111-24.

Weiler E | Volume 1; Issue 1 (2021) | JNOR-1(1)-002 | Research Article 
30. Zhuchenko O, Bailey J, Bonnen P, Ashizawa T, Stockton DW, Amos C, et al. Autosomal dominant cerebellar ataxia (SCA6) associated with small polyglutamine expansions in the alpha 1A-voltage-dependent calcium channel. Nat Genet. 1997;15(1):62-9.

31. Nagaoka U, Takashima M, Ishikawa K, Yoshizawa K, Yoshizawa T, Ishikawa M, et al. A gene on SCA4 locus causes dominantly inherited pure cerebellar ataxia. Neurology. 2000;54(10):1971-5.

32. Armutlu K, Karabudak R, Nurlu G. Physiotherapy approaches in the treatment of ataxic multiple sclerosis: a pilot study. Neurorehabil Neural Repair. 2001;15(3):203-11.

33. Manto M, Bower JM, Conforto AB, Delgado-Garcia JM, da Guarda SN, Gerwig M, et al. Consensus paper: roles of the cerebellum in motor control-the diversity of ideas on cerebellar involvement in movement. Cerebellum. 2012;11(2):457-87.

34. Mills RJ, Yap L, Young CA. Treatment for ataxia in multiple sclerosis. Cochrane Database Syst Rev. 2007;24(1):CD005029.

35. Marquer A, Barbieri G, Pérennou D. The assessment and treatment of postural disorders in cerebellar ataxia: a systematic review. Ann Phys Rehabil Med. 2014;57(2):67-78.

36. Stevens V, Goodman K, Rough K, Kraft GH. Gait impairment and optimizing mobility in multiple sclerosis. Phys Med Rehabil Clin N Am. 2013;24(4):573-92.

37. Marsden J, Harris C. Cerebellar ataxia: pathophysiology and rehabilitation. Clin Rehabil. 2011;25(3):195216.

38. Peterson EW, Cho CC, von Koch L, Finlayson ML. Injurious falls among middle aged and older adults with multiple sclerosis. Arch Phys Med Rehabil. 2008;89(6):1031-37.

39. Hatakenaka M, Miyai I, Mihara M, Yagura H, Hattori N. Impaired motor learning by a pursuit rotor test reduces functional outcomes during rehabilitation of poststroke ataxia. Neurorehabil Neural Repair. 2012;26(3):293-300.

40. Boyd LA, Winstein CJ. Cerebellar stroke impairs temporal but not spatial accuracy during implicit motor learning. Neurorehabil Neural Repair. 2004;18(3):134-43.

41. Kim BR, Lim JH, Lee SA, Park S, Koh SE, Lee IS, et al. Usefulness of the scale for the assessment and rating of ataxia (SARA) in ataxic stroke patients. Ann Rehabil Med. 2011;35(6):772-80.

42. Richards L, Senesac C, McGuirk T, Woodbury M, Howland D, Davis S, et al. Response to intensive upper extremity therapy by individuals with ataxia from stroke. Top Stroke Rehabil. 2008;15(3):262-71.

43. Revuelta GJ, Wilmot GR. Therapeutic interventions in the primary hereditary ataxias. Curr Treat Options Neurol. 2010;12(4):257-73.

44. Vogel AP, Keage MJ, Johansson K, Schalling E. Treatment for dysphagia (swallowingdifficulties) in hereditary ataxia. Cochrane Database Syst Rev. 2015;13(11):CD010169.

45. Mills RJ, Yap L, Young CA. Treatment for ataxia in multiple sclerosis. Cochrane Database Syst Rev. 2007;24(1):CD005029.

46. Pandolfo M, Manto M. Cerebellar and afferent ataxias. Continuum (Minneap Ilg W, Bastian AJ, Boesch S, Burciu RG, Celnik P, Claassen J, et al. Consensus paper: management of degenerative cerebellar disorders. Cerebellum. 2014;13(2):248-68.

47. Baier B, Bense S, Dieterich M. Are signs of ocular tilt reaction in patients with cerebellar lesions mediated by the dentate nucleus? Brain. 2008;131(6):1445-54.

48. Baier B, Dieterich M. Pusher syndrome in patients with cerebellar infarctions? J Neurol. 2012;259(7):14689.

49. Grodd W, Hülsmann E, Lotze M, Wildgruber D, Erb M. Sensorimotor mapping of the human cerebellum: fMRI evidence of somatotopic organization. Hum Brain Mapp. 2001;13(2):55-73.

50. Morton SM, Bastian AJ. Relative contributions of balance and voluntary leg-coordination deficits to cerebellar gait ataxia. J Neurophysiol. 2003;89(4):1844-56.

51. Tani K, Matsugi A, Uehara S, Kimura D. Abnormal bias in subjective vertical perception in a post-stroke astasia patient. J Phys Ther Sci. 2016;28(10):2979-83.

52. Reinhart S, Schaadt AK, Keller I, Hildebrandt H, Kerkhoff G, Utz K. Rotational coherent dot movement normalizes spatial disorientation of the subjective visual vertical in patients with rightsided stroke. Neuropsychologia. 2016;92:174-80.

Weiler E | Volume 1; Issue 1 (2021) | JNOR-1(1)-002 | Research Article 